Linköping Studies in Science and Technology

Licentiate Thesis No. 1650

\title{
Contributions to the theory of peaked solitons
}

Marcus Kardell

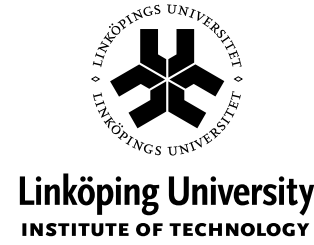

Department of Mathematics, Division of Mathematics and Applied Mathematics Linköping University, SE-581 83 Linköping, Sweden

Linköping 2014 


\section{Contributions to the theory of peaked solitons}

\section{Marcus Kardell}

Linköping Studies in Science and Technology. Licentiate Thesis No. 1650.

ISSN 0280-7971

ISBN 978-91-7519-373-1

Copyright (C)2014 Marcus Kardell, unless otherwise noted

Printed by LiU-Tryck, Linköping, Sweden, 2014

This is a Swedish Licentiate Thesis.

The Licentiate degree comprises 120 ECTS credits of postgraduate studies. 


\section{Abstract}

The aim of this work is to present some new contributions to the theory of peaked solitons. The thesis contains two papers, named "Lie symmetry analysis of the Novikov and GengXue equations, and new peakon-like unbounded solutions to the Camassa-Holm, DegasperisProcesi and Novikov equations" and "Peakon-antipeakon solutions of the Novikov equation" respectively.

In the first paper, a new kind of peakon-like solutions to the Novikov equation is obtained, by transforming the one-peakon solution via a Lie symmetry transformation. This new kind of solution is unbounded as $x \rightarrow+\infty$ and/or $x \rightarrow-\infty$. It also has a peak, though only for some interval of time. We make sure that the peakon-like function is still a solution in the weak sense for those times where the function is non-differentiable. We find that similar solutions, with peaks living only for some interval in time, are valid weak solutions to the Camassa-Holm equation, though these can not be obtained via a symmetry transformation.

The second paper covers peakon-antipeakon solutions of the Novikov equation, on the basis of known solution formulas from the pure peakon case. A priori, these formulas are valid only for some interval of time and only for some initial values. The aim of the article is to study the Novikov multipeakon solution formulas in detail, to overcome these problems. We find that the formulas for locations and heights of the peakons are valid for all times at least in an ODE sense. Also, we suggest a procedure of how to deal with multipeakons where the initial conditions are such that the usual spectral data are not well-defined as residues of single poles of a Weyl function. In particular we cover the interaction between one peakon and one antipeakon, revealing some unexpected properties. For example, with complex spectral data, the solution is shown to be periodic, except for a translation, with an infinite number of collisions between the peakon and the antipeakon. Also, plotting solution formulas for larger number of peakons shows that there are similarities to the phenomenon called "waltzing peakons". 


\section{Populärvetenskaplig sammanfattning}

Inom vågteori studeras så kallade solitoner, vilka kan beskrivas som vågpaket som rör sig med konstant form och hastighet. Typiska egenskaper är att utbredningen i rummet är begränsad, samt att två solitoner som kolliderar kan passera genom varandra utan att ändra form.

Fenomenet beskrevs redan 1834 av John Scott Russell, som ridande längs en kanal följde en "rundad, slät, väldefinierad upphöjning av vatten, vilken fortsatte sin bana längs kanalen synbarligen utan att ändra form eller förlora fart". Dåvarande våglära kunde inte förklara uppkomsten av sådana vågor, men moderna hydrodynamiska teorier innehåller ett antal modeller där solitoner är ett naturligt koncept.

I denna avhandling studeras vågekvationer som tillåter en särskild typ av spetsiga solitoner, så kallade peakoner (från engelskans 'peaked soliton'). Avhandlingen utgörs av två artiklar som på olika sätt bidrar till grundförståelsen av detta fenomen.

I Artikel 1 beskrivs en ny typ av peakon-liknande våg där den spetsiga vågtoppen endast existerar under ett visst tidsintervall. Denna typ av våg kan visas förekomma i flera moderna vågekvationer, såsom Camassa-Holm-ekvationen och Novikovs ekvation.

I Artikel 2 studeras, i fallet med Novikovs ekvation, samspelet mellan peakoner och så kallade antipeakoner, vilket är vågor med spetsig vågdal istället för vågtopp. Artikeln beskriver vad som händer då peakoner kolliderar med antipeakoner, både i allmänhet och i några specialfall. 
iv 


\section{Acknowledgements}

First, I want to thank Hans Lundmark, who has all the qualities one could ask for in a supervisor. Here's hoping that we will find more peakon results in the future! Thanks also to my co-supervisors Stefan Rauch and Joakim Arnlind for reading manuscripts and providing valuable comments. Thanks to colleagues and fellow Ph.D. students at Linköping University for making this a nice place to work at. And finally, thanks to family and friends that always support me and make my life so much better.

Thank you. 
vi 


\section{Contents}

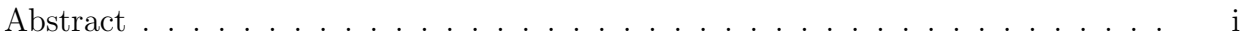

Populärvetenskaplig sammanfattning . . . . . . . . . . . . . . iii

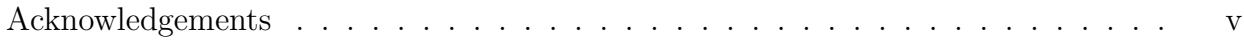

Introduction 1

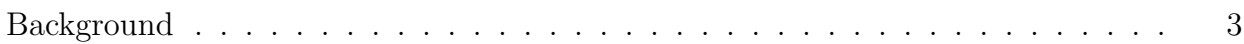

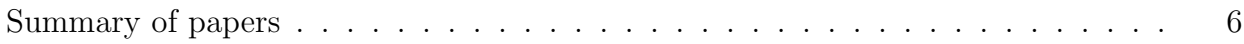

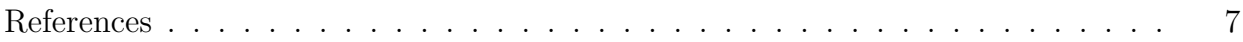

Paper I: Lie symmetry analysis of the Novikov and Geng-Xue equations, and new peakon-like unbounded solutions to the Camassa-Holm, Degasperis-Procesi and Novikov equations

1 Introduction $\quad 11$

2 Definitions $\quad 12$

3 Using Jets 14

3.1 Jets and the Novikov equation . . . . . . . . . . . . . . . . . . . . . . 14

3.2 Jets and the Geng-Xue system . . . . . . . . . . . . . . . . . . 16

4 Results $\quad 18$

4.1 Symmetries of the Novikov equation . . . . . . . . . . . . . . . . . . . . . . . . . . . . . .

4.2 Symmetries of the Geng-Xue equations . . . . . . . . . . . . . . . . . . . 18

4.3 Transforming a one-peakon solution . . . . . . . . . . . . . . . . 19

5 Peakon creation in related equations 23

5.1 Camassa-Holm solutions with peakon creation . . . . . . . . . . . . . 23

5.2 Degasperis-Procesi solutions with peakon creation? . . . . . . . . . 25

Paper II: Peakon-antipeakon solutions of the Novikov equation 29

1 Introduction 31

2 Summary of known results for the pure peakon case 33

3 Peakon-antipeakon collisions $\quad 36$ 
4 Dynamics of one peakon-antipeakon pair $\quad 40$

4.1 Peakon-antipeakon pair, positive distinct eigenvalues . . . . . . . . . . . . . . 43

4.2 Peakon-antipeakon pair, complex conjugated eigenvalues . . . . . . . . . . . . 45

4.3 Peakon-antipeakon pair, eigenvalue with multiplicity two . . . . . . . . . 50

5 The general peakon-antipeakon case $\quad 53$

5.1 Range of eigenvalues for peakon-antipeakon solutions . . . . . . . . . . . . 53

5.2 Multipeakon solutions with distinct eigenvalues . . . . . . . . . . . . 55

5.3 Eigenvalues of multiplicity greater than one . . . . . . . . . . . . . . 61 


\section{Introduction}




\section{Introduction}

This licentiate thesis presents some contributions to the theory of peaked soliton solutions, so called peakons, in a number of partial differential equations. In the Background section, the relevant equations are introduced together with the concept of peakons, which are solutions to these equations in a certain weak sense. A short overview of known results in the field is also given.

The results of the thesis are then presented in two separate articles. Paper I is a submitted article named "Lie symmetry analysis of the Novikov and Geng-Xue equations, and new peakon-like unbounded solutions to the Camassa-Holm, Degasperis-Procesi and Novikov equations". Paper II is coauthored with Hans Lundmark, and is named "Peakon-antipeakon solutions of the Novikov equation".

\section{Background}

In this section we define the concept of peaked solitons, or peakons. We give a short historical overview describing the partial differential equations of interest to us, and what is known about peakon solutions to these equations. Throughout the thesis we use subscripts to denote partial derivatives.

The equations of interest in this thesis are joined by the fact that they are integrable, a property characterized among other things by the existence of an infinite number of constants of motion and the possibility to find explicit solutions formulas. In particular these equations admit peakon solutions, to be defined shortly.

The first object of interest is the $b$-family of third order quadratically nonlinear PDEs,

$$
u_{t}-u_{x x t}=-(b+1) u u_{x}+b u_{x} u_{x x}+u u_{x x x}, \quad(x, t) \in \mathbb{R}^{2},
$$

where $u=u(x, t)$ is a function of the space and time coordinates. This family includes (with $b=2$ ) the dispersionless version of the much studied Camassa-Holm $(\mathrm{CH})$ equation [4], which was first developed in 1993 as a model of shallow water waves. If one instead chooses $b=3$ in (1), it turns into the Degasperis-Procesi (DP) equation [9] from 1999, which has also been found to have hydrodynamical relevance [7].

Both equations are of interest in wave theory as they accomodate wave breaking, i.e., the slope of the wave profile may tend to infinity in finite time. It is only for $b=2$ and $b=3$ that the equations in the family are integrable, according to a number of integrability tests $[9,19,13,15]$. Both the $\mathrm{CH}$ and the DP equations appear in Paper I.

Most prevalent in the thesis is the more recent Novikov equation $[20,14]$

$$
u_{t}-u_{x x t}=-4 u^{2} u_{x}+3 u u_{x} u_{x x}+u^{2} u_{x x x},
$$

which appears in both papers. This equation has a similar structure to $\mathrm{CH}$ and DP, but instead has cubic nonlinearities in the right hand side. 
In Paper II we also briefly study the Geng-Xue (GX) system [10]

$$
\left\{\begin{array}{l}
u_{x x t}-u_{t}=\left(u_{x}-u_{x x x}\right) u v+3\left(u-u_{x x}\right) v u_{x}, \\
v_{x x t}-v_{t}=\left(v_{x}-v_{x x x}\right) u v+3\left(v-v_{x x}\right) u v_{x},
\end{array}\right.
$$

which can be thought of as a two-component generalization of the Novikov equation, e.g., with $u=v$ the system reduces to two copies of (2).

All of the equations above are joined by the fact that they admit so called peakon solutions. The word peakon is short for 'peaked soliton', where soliton means solitary wave (pulse), and peaked means that there is some point $x(t)$ where the left and right derivatives do not coincide. The general expression for peakons, as far as we are concerned, is

$$
u(x, t)=m(t) e^{-|x-x(t)|}= \begin{cases}m(t) e^{-x+x(t)}, & x \geq x(t), \\ m(t) e^{x-x(t)}, & x \leq x(t) .\end{cases}
$$

Thus, the basic shape of the peakon for a fixed $t$ is that of $e^{-|x|}$, with $m(t)$ governing the height, and $x(t)$ the position of the center of the wave pulse.

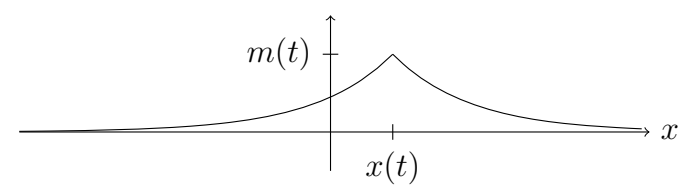

If $m(t)<0$, the wave profile instead has a trough (downward pointing peak), and we call this an antipeakon.

One reason that peakon solutions of these equations are of interest, is that they behave nicely under taking linear combinations, despite the nonlinearity of the equations. Let us denote a sum of peakons,

$$
u(x, t)=\sum_{k=1}^{n} m_{k}(t) e^{-\left|x-x_{k}(t)\right|},
$$

with the term multipeakon. Sometimes one assumes $m_{k}>0$, the so called pure peakon case, whereas all $m_{k}<0$ corresponds to the pure antipeakon case. The remaining case, where not all $m_{k}$ have the same sign, we call the mixed peakon/antipeakon case.

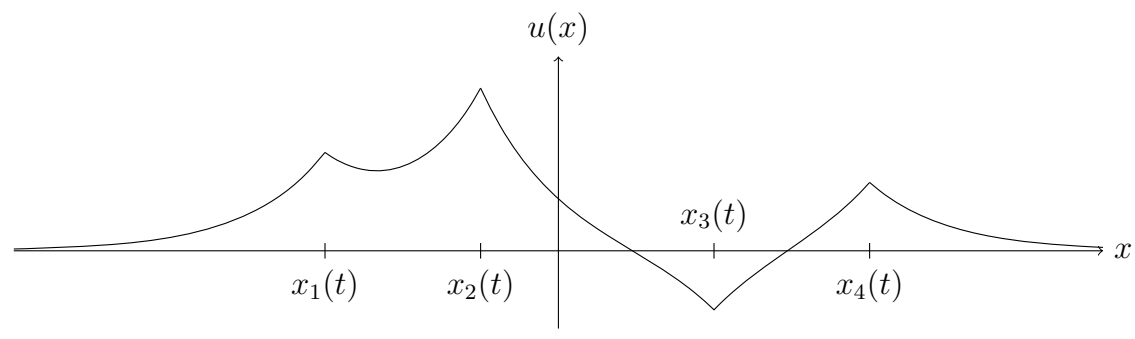


Note that the multipeakons can not be solutions to these PDEs in a strong sense, since they are non-differentiable. The problem lies in multiplying the first and the second derivative of $u$ with respect to $x$, since $u_{x x}$ contains Dirac deltas exactly at the jump discontinuities of $u_{x}$. To solve this, one rewrites the $b$-family (1) as

$$
\left(1-\partial_{x}^{2}\right) u_{t}+\left(b+1-\partial_{x}^{2}\right) \partial_{x}\left(\frac{1}{2} u^{2}\right)+\partial_{x}\left(\frac{3-b}{2} u_{x}^{2}\right)=0 .
$$

Then a function $u(x, t)$ is said to be a weak solution if $u(\cdot, t) \in W_{\text {loc }}^{1,2}(\mathbb{R})$ for each fixed $t$, i.e., $u(\cdot, t)^{2}$ and $u_{x}(\cdot, t)^{2}$ are locally integrable functions, and (6) is satisfied for all $t$ in the distributional sense.

Similarly, to define weak solutions of the Novikov equation we follow [12] and write (2) as

$$
\left(1-\partial_{x}^{2}\right) u_{t}+\left(4-\partial_{x}^{2}\right) \partial_{x}\left(\frac{1}{3} u^{3}\right)+\partial_{x}\left(\frac{3}{2} u u_{x}^{2}\right)+\frac{1}{2} u_{x}^{3}=0 .
$$

We require that $u(\cdot, t) \in W_{\text {loc }}^{1,3}(\mathbb{R})$ for all $t$, so that $u^{3}$ and $u_{x}^{3}$ are locally integrable. It then follows from Hölder's inequality with conjugate indices 3 and $\frac{3}{2}$ that the term $u u_{x}^{2}$ is locally integrable as well, so it makes sense to call $u$ a weak solution to the Novikov equation if (7) is satisfied distributionally.

It is worth mentioning that the Degasperis-Procesi equation is slightly different from the others when it comes to weak solutions. One has that functions in $W_{\text {loc }}^{1, p}(\mathbb{R})$ are continuous by the Sobolev embedding theorem, but if one puts $b=3$ in (6), the term $u_{x}^{2}$ disappears, so one only has to require that $u(\cdot, t) \in L_{\text {loc }}^{2}(\mathbb{R})$. Thus the Degasperis-Procesi equation admits solutions that are not continuous, see for example $[16,5,6]$, while $\mathrm{CH}$ and Novikov do not.

There are a number of papers concerning dynamics of peakons in the $\mathrm{CH}$, DP, Novikov and GX equations. A few will be mentioned here, to put the results of the thesis into context.

With the $n$-peakon ansatz (5), our PDEs are easily seen to be satisfied on the intervals where the multipeakon is differentiable, since each exponential function is a solution. Studying what goes on at the points of each peak, the PDEs simplify into a system of $2 n$ ODEs in the variables $\left(x_{k}, m_{k}\right)$, which denote the position and height respectively of peakon $k$. For the Camassa-Holm $b$-family, this system is

$$
\left\{\begin{array}{l}
\dot{x}_{k}=\sum_{i=1}^{n} m_{i} e^{-\left|x_{k}-x_{i}\right|} \\
\dot{m}_{k}=(b-1) m_{k} \sum_{i=1}^{n} m_{i} \operatorname{sgn}\left(x_{k}-x_{i}\right) e^{-\left|x_{k}-x_{i}\right|},
\end{array}\right.
$$

where we use the convention that $\operatorname{sgn} 0=0$.

For $n=1$, the system reduces to

$$
\left\{\begin{array}{l}
\dot{x}_{1}=m_{1} \\
\dot{m}_{1}=0
\end{array}\right.
$$

which means that the peakon $u(x, t)=m_{1} e^{-\left|x-m_{1} t\right|}$ really is a soliton, maintaining its shape and height, travelling with constant speed equal to its height. Note that in this case $(\mathrm{CH}$ and DP), antipeakons move to the left while peakons move to the right. 
A similar system can be constructed for peakon dynamics in the Novikov equation. One finds that a single peakon travels with constant speed equal to the square of its height. Thus, both peakons and antipeakons move to the right in the Novikov equation, which gives rise to some new phenomena in Paper II.

For $n>1$, the interaction between peakons makes the ODE systems considerably more complicated. The system (8) was solved in the pure peakon sector using inverse scattering techniques for Camassa-Holm in [1], and for Degasperis-Procesi in [17]. The mixed case was studied in [2] and [21] for $\mathrm{CH}$ and DP respectively. Pure multipeakon solutions to Novikov and GX were studied in [12] and [18] respectively.

In the pure peakon sector, there are no collisions amongst peakons, i.e., the coordinates $x_{1}(t)<x_{2}(t)<\cdots<x_{n}(t)$ remain separated for all times. This is not necessarily true in the mixed case, where collisions may occur, causing some $m_{k}$ to tend to infinity. Thus one has to be careful with the meaning of continuing a solution beyond a collision. In [11] it is shown how to obtain global multipeakon solutions of the Camassa-Holm equation, by introducing a new system of ODEs which is well-posed even at collisions. See also [3] for how to resolve singularities for more general kinds of solutions of the Camassa-Holm equation.

\section{Summary of papers}

\section{Paper I}

The first paper, which has been submitted, is named "Lie symmetry analysis of the Novikov and Geng-Xue equations, and new peakon-like unbounded solutions to the Camassa-Holm, Degasperis-Procesi and Novikov equations". In this paper, a new kind of peakon-like solutions to the Novikov equation is obtained, by transforming the one-peakon solution via a Lie symmetry transformation.

This new kind of solution is unbounded as $x \rightarrow+\infty$ and/or $x \rightarrow-\infty$. It also has a peak, though only for some interval of time. We make sure that the peakon-like function is still a solution in the weak sense for those times where the function is non-differentiable.

To find this class of solutions we calculate the symmetry group of the Novikov equation, which might be of some interest in itself. While doing this, we also calculate the symmetry group of the GX system. Both symmetry groups are presented in the paper.

Finally, we find that similar solutions, with peaks living only for some interval in time, are valid weak solutions to the Camassa-Holm equation, though these can not be obtained via a symmetry transformation.

\section{Paper II}

The second paper, yet unsubmitted, named "Peakon-antipeakon solutions of the Novikov equation", is coauthored with H. Lundmark. It follows closely in the footsteps of [12], where explicit solutions formulas were given in terms of suitable spectral data for the Novikov equation in the pure peakon sector. Paper II covers the mixed peakon/antipeakon case, 
where the same formulas a priori are valid only for some interval of time and only for some initial values.

The aim of the paper is to study the Novikov multipeakon solution formulas in detail, to overcome these problems. We find that the formulas for the locations and heights of the peakons are valid for all times at least in an ODE sense. Also, we suggest a procedure of how to deal with multipeakons where the initial conditions are such that the usual spectral data are not well-defined as residues of single poles of a Weyl function.

In particular we cover the interaction between one peakon and one antipeakon, revealing some unexpected properties. For example, with complex spectral data, the solution is periodic (except for a translation), with an infinite number of collisions between the peakon and the antipeakon. Also, plotting solution formulas for larger number of peakons shows that there are similarities to the phenomenon called "waltzing peakons" in [8].

\section{References}

[1] Beals R., Sattinger D., Szmigielski J., Multi-peakons and a theorem of Stieltjes, Inverse Problems, 15(1):L1-L4, 1999.

[2] Beals R., Sattinger D., Szmigielski J., Multipeakons and the classical moment problem, Advances in Mathematics, 154:229-257, 2000.

[3] Bressan A., Constantin A., Global conservative solutions of the Camassa-Holm equation, Arch. Ration. Mech. Anal., 183(2):215-239, 2007.

[4] Camassa R., Holm D., An integrable shallow water equation with peaked solitons, Phys. Rev. Lett., 71(11):1661-1664, 1993.

[5] Coclite G., Karlsen K., On the well-posedness of the Degasperis-Procesi equation, J. Funct. Anal., 233(1):60-91, 2006.

[6] Coclite G., Karlsen K., On the uniqueness of discontinuous solutions to the DegasperisProcesi equation, J. Differential Equations, 234(1):142-160, 2007.

[7] Constantin A., Lannes D., The hydrodynamical relevance of the Camassa-Holm and Degasperis-Procesi equations, Archive for Rational Mechanics and Analysis, 192(1):165-186, 2009.

[8] Cotter C., Holm D., Ivanov R., Percival J., Waltzing peakons and compacton pairs in a cross-coupled Camassa-Holm equation, J. Phys. A: Math. Theor, 44(26):265205, 2011.

[9] Degasperis A., Procesi M., Asymptotic integrability, Symmetry and perturbation theory (SPT 98, Rome), 23-37, 1999.

[10] Geng X., Xue B., An extension of integrable peakon equations with cubic nonlinearity, Nonlinearity, 22(8):1847-1856, 2009. 
[11] Holden H., Raynaud X., Global conservative multipeakon solutions of the CamassaHolm equation, J. Hyperbolic Diff. Eq., 4(1):39-64, 2007.

[12] Hone A. N. W., Lundmark H., Szmigielski J., Explicit multipeakon solutions of Novikov's cubically nonlinear integrable Camassa-Holm type equation, Dynamics of Partial Differential Equations, 6(3):253-289, 2009, arXiv:0903.3663 [nlin.SI].

[13] Hone A., Wang J., Prolongation algebras and Hamiltonian operators for peakon equations, Inverse Problems, 19(1):129-145, 2003.

[14] Hone A., Wang J., Integrable peakon equations with cubic nonlinearity, J. Phys. A, 41(37):372002, 2008.

[15] Ivanov R., On the integrability of a class of nonlinear dispersive wave equations, $J$. Nonlinear Math. Phys., 12(4):462-468, 2005.

[16] Lundmark H., Formation and dynamics of shock waves in the Degasperis-Procesi equation, J. Nonl. Sci., 17(3):169-198, 2007.

[17] Lundmark H., Szmigielski J., Degasperis-Procesi peakons and the discrete cubic string, IMRP Int. Math. Res. Pap., 2005(2):53-116, 2005.

[18] Lundmark H., Szmigielski J., An inverse spectral problem related to the Geng-Xue two-component peakon equation, arXiv:1304.0854 [nlin.SI], 2013.

[19] Mikhailov A., Novikov V., Perturbative symmetry approach, J. Phys. A., 35(22):47754790, 2002.

[20] Novikov V., Generalizations of the Camassa-Holm equation, J. Phys. A, 42(34):342002, 14, 2009.

[21] Szmigielski J., Zhou L., Peakon-antipeakon interactions in the Degasperis-Procesi Equation, arXiv:1301.0171 [nlin.SI], 2013. 


\section{Papers}

The articles associated with this thesis have been removed for copyright reasons. For more details about these see:

http://urn.kb.se/resolve?urn=urn:nbn:se:liu:diva-105710 